\title{
The design of Thermoplastic packaging and products maker for Small and Medium Enterprises (SMEs) in Indonesia
}

\author{
Dian Cahyadi ${ }^{* 1}$, Lanta L ${ }^{2}$, Nurabdiansyah ${ }^{3}$, Muhammad Farid ${ }^{4}$ \\ 1,2,3 Arts and Design Faculty, Universitas Negeri Makassar, Indonesia \\ *e-mail: dian.cahyadi@unm.ac.id \\ ${ }^{4}$ Faculty of Engineering, Universitas Negeri Makassar, Indonesia
}

\begin{abstract}
The production technology of packaging and other products based on plastic material is not as complicated as many people think. This research is a study to find the proper method to use in the design of packaging and plastics maker tools. The product is dedicated to (Small and Medium Enterprises (SMEs) in Indonesia to encourage them to produce products with attractive packaging. By the creation of this toolmaker is also expected to be potentially marketable for industrial development based on the use of materials from plastic. The literature study method is used to collect all pertinent information about appropriate methods, systems, and technical molding that can be used to form the basis of application of design materials. The methods can be applied to the design plan of packaging equipment and plastic products. This research is based the basic concepts of engineering principles of equipment consisting of heating and forming process using vacuum cleaner machine tool that is easily obtained and prepare the box facilities that can be obtained around our environment. In addition, by understanding the engineering principles of equipment, vacuum forming can be done. This research shows that using Thermoplastic can produce not only the packaging that is the specific purpose of this research activity, but also has the potential market space to produce a wide range of other creative products.
\end{abstract}

\section{Keywords:}

Molding; thermo forming; SMEs development.

\section{INTRODUCTION}

Produce plastic products with various forms and functions known today, are industrial products manufactured using molding techniques and die casting techniques. Especially among small and medium enterprises (SMEs), generally depends on products made of plastic. Constraints faced by small and medium industry players is the choice of products offered by the market is very limited, especially if related to the value of differentiation that would be produced as a differentiator with other products. Another obstacle is that the industry engaged in the plastic industry is still lacking, so that SMEs depend on the industry in China. Indeed, molding equipment to produce goods made of plastic material can be produced at an affordable price for SMEs. Because the molding manufacturing technology to produce threedimensional objects can be made with many prototypes and according to production needs (Anita, 2016; Badan Pusat Statistik Provinsi Sulawesi Selatan, 2017). The purpose of writing the results of this study is to obtain an overview of the methods and systems to be used in the design of packaging equipment that will produce the model and prototype.

\section{2 МЕTHOD}

The method used in this study is a literature study related to production technology made from polymer / thermoplastic obtained from various sources (Geoff, 2016; Kopeliovich, 2014).

\section{RESULTS AND DisCUSSIONS}

\subsection{Packaging Function}

The basic data obtained in this study on plastic packaging is a polymer material processing technology, which is related to the processing of polymers into several forms and related explanation of the process of converting polymer materials into products. Kotler and Armstrong (2017) define "packaging involves designing and producing the container or wrapper for a product" which means the packaging process involves designing and producing activities, the main function of the packaging itself is to protect the product to keep the product maintained. Packaging is then defined as the whole activity of designing and producing containers or packs or packaging of a product. Packaging includes three things, namely the brand, the packaging itself and the label. There are three main reasons for wrapping. Firstly, packaging meets the requirements of security and expediency. Packaging protects the product on its way from producer to consumer. Secondly, packaging can provide information and product identification becomes more effective and in itself prevents the exchange by competitors' products. In addition, the way companies differentiate their products. Thirdly, packaging is a way to increase corporate profits. With a very attractive packaging is expected to attract and attract the attention of consumers. In addition, packaging can also reduce the possibility of damage to the goods and ease of delivery.

Kertajaya (2006), a marketing expert, says that technology has made packaging functional, used to say, "Packaging protects what it sells." Now, "Packaging sells what it protects". What is expressed by Kertajaya (2006) function as a protector or container but must be able to sell the packaged products through visual display that is interesting, evocative, and fascinating for consumer. The functional development of packaging does not just stop there (Klimchuk \& Krasovec, 2018). Packaging can also serve to communicate a particular image. For example, Japanese food products, the Japanese are known to be the smartest to make good packaging as presented in Figure 1 below. 


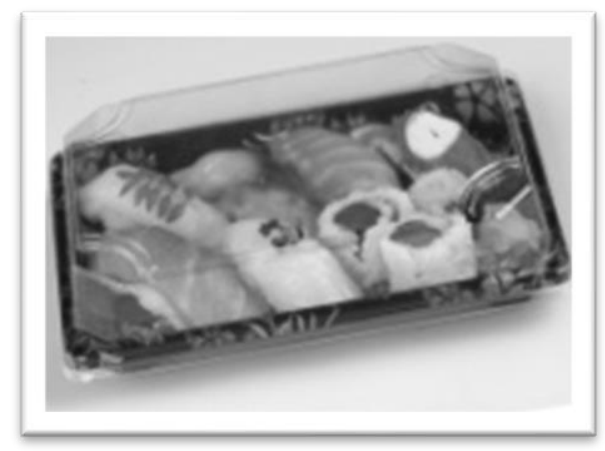

Figure 1. Sushi packaging produced by thermoforming machine

Seen packaging that is made other than other products (stands out) and sometimes they dare to use expensive materials to wrap the products sold. Although there is no message written on the wrapper, but the packaging communicates a good image. Therefore, that the packaging presented in supermarket will not be drowned by other competitor products. By looking at a very important packaging function, the packaging functional concept should cover the entire marketing process from product conception to end-user (Kertajaya, 2006).

The structure of the design related to the physical features of the packaging consists of 3 sub-dimensions, they are shape, size, and materials. The forms affect the protection and security functions in touching, pouring, and storing (Smith, Smith, \& Zook, 2011). The simpler form is more attractive than the usual, and the rectangle is more preferable than the box (9). Sizes are also associated with dimensions to production costs, related to mass or net dosage, as well as the packaging dimensions, associated shipping costs, and affecting the shape of the product itself. That is how to rate the number of objects, time, or situation in accordance with certain rules. The material considerations referred to in this problem are on the psychological approach, that the packaging materials used should be able to provide convenience for the consumer to perceive that the price is related to quality (Smith et al., 2011).

\subsection{Packaging Product Information}

The inherent information on the product can help the consumer in making purchasing decisions more carefully (Silayoi \& Speece, 2004). Especially for food products on their packaging must include; brand, composition, net weight, manufacturer address, production code, expiration period, production number of Household Industry (Supardi \& Sukamto, 1999). Material Requirements for Aspects of product quality to be protected are a key consideration in determining to select the packaging material used. The quality of the product when it reaches the consumer depends on the condition of raw materials, processing methods and storage conditions.

Thus the packaging function must meet the following requirements(Klimchuk \& Krasovec, 2018):

- Good wrapping capability to facilitate handling, transport, distribution, storage and compilation / buildup.

- The ability to protect its contents from a variety of external risks, such as protection from hot / cold air, sunlight, odor, mechanical stress, microorganism contamination.

- Ability as an attraction to consumers. In this case identification, information and appearance such as shape, color and beauty of packaging materials should get attention.

- Economic requirements, i.e. ability to meet market desires, target communities, and destination places.

- Has the size, shape and weight that conform to existing norms or standards, is easy to dispose of, and is easily molded or molded.

With the requirement that must be fulfilled the packaging then the mistake in choosing the packaging raw materials, the mistake of choosing the packaging design and the mistake in choosing the type of packaging, can be minimized. To meet these requirements the packaging must have the following properties:

- Permeable to air (oxygen and other gases).

- It is non-toxic and inert (does not react and causes chemical reactions) to maintain the color, flavor, and taste of the packaged product.

- Waterproof (able to hold water or moisture around it).

- Strong and not easy to leak.

- Relatively heat resistant.

- Easy to work in bulk and relatively cheap price.

\subsection{Advantages and Disadvantages of Paper and Plastic Packaging Materials}

The function of packaging is to protect products and goods so as not to be contaminated by other materials. Damage to a product can also be prevented using packaging. In terms of promotion, shape, color, and decoration packaging can also attract the attention of prospective customers to buy the product. Packaging can come from a wide variety of materials. However, the material that is often used for packaging is paper and plastic. Both materials must have advantages and disadvantages of each. Here are the advantages and disadvantages of the following paper and plastic packaging (Jaswin, 2008). 


\subsubsection{Paper packaging}

Paper packaging is usually used to wrap food. As packaging, paper has many advantages. In addition to lightweight materials, paper packaging is also relatively cheaper than the packaging of other materials. It is also easy to store and recycle. It is just the lack of paper packaging is easily torn, flammable, cannot be heated for too long. Paper packaging cannot be used to wrap the liquid. So choose a paper material that is suitable for food packaging or not into consideration. Therefore, currently most manufacturers choose the use of paper tailored to the type of product. Figure 2 below is an example of packaging use paper on the outside as an aesthetic element whereas plastic is used on the inside for endurance function or product life.

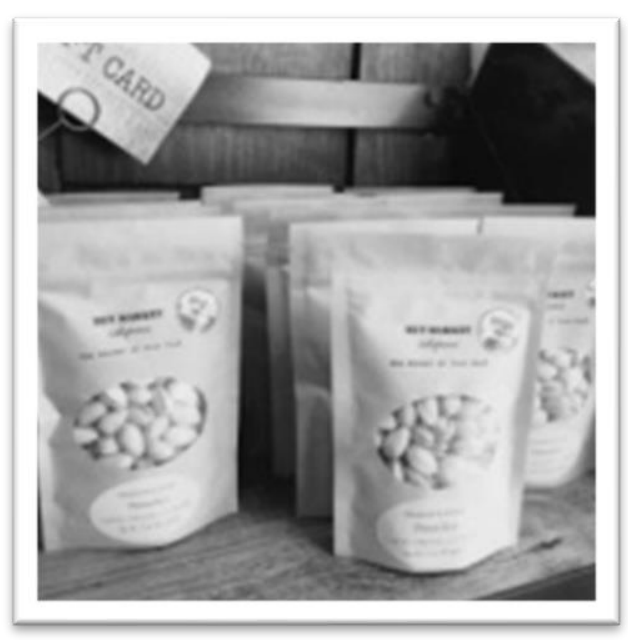

Figure 2. Examples of paper packaging (12)

\subsubsection{Packaging plastic materials}

The plastic material has a plastic packing texture is very strong compared to paper packaging. In addition, plastic packaging is not easily leaky, lightweight, and can be used to wrap liquids. However, plastic packaging also has some deficiencies, which contain chemicals that harm health, cannot stand the heat with high temperatures. Counterfeiting brands on products that use plastic packaging often occur. Of all the packaging materials on the market, the most widely used plastic today; this is due to the highly flexible and dynamic yet strong plastic properties. Several types of plastic materials commonly used as the main material of packaging include polyethylene, cellophan, polyvinylchloride (PVC), polyvinyl dienachloride (PVDC), polypropylene, polyester, polyamide, and polyethylentereptalate (PET). Due to the nature of the chemical material and can react directly with human health, the thermoplastic material is then classified to some coding according to its product designation, as in the following figure. Figure 3 below shows the example of pouch, which is made of plastic materials have advantages that are lightweight, not easy to leak, and can be used to wrap the liquid.

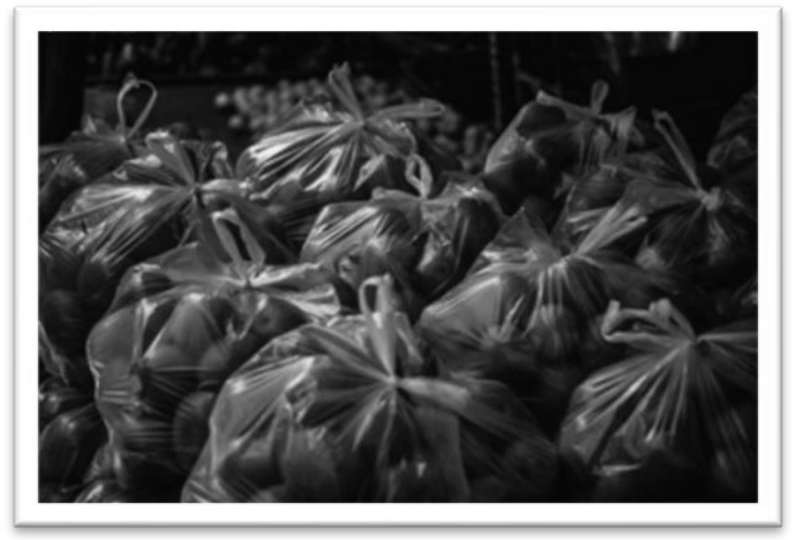

Figure 3. Example of plastic packaging (Kemasaja Team, 2019)

\subsubsection{Plastic packaging code}

Polyethylene is a polymer of an ethylene monomer prepared by an addition polymerization process of ethylene gas obtained from byproducts of the oil and coal industry. Polyethylene is a soft, transparent, and flexible film has good impact strength and tear strength. Heating polyethylene will cause this plastic to be soft and liquid at $110^{\circ} \mathrm{C}$. The nature of its low permeability and good mechanical properties, the polyethylene with thickness of $0.001-0.01$ inches is widely used to pack food. Polyethylene plastics include thermoplastic groups that can be formed into pockets of good density. Based on the density, the polyethylene is divided into 4, namely Low Density Polyethylene (LDPE), Medium Density Polyethylene (MDPE), High Density Polyethylene (HDPE), and Linear-low-density polyethylene (LLDPE) ethylene copolymers with small amounts of butane, hexane, or octane, thus having branches on the main chain at regular intervals. LLDPE is stronger than LDPE and its heat sealing properties are also better(Julianti \& Nurminah, 2006). 
Table 1. Plastic packaging code by type and designation (Buckle \& Buckel, 1978)

\begin{tabular}{|c|c|c|}
\hline Symbol & Acromym & Full name and uses \\
\hline & PET & $\begin{array}{l}\text { Polyethylene terephthalate - Fizzy drink } \\
\text { bottles and fromen ready meal packages. }\end{array}$ \\
\hline & HDPE & $\begin{array}{l}\text { High-density polyethylene - Milk and } \\
\text { washing-up liquid bottles }\end{array}$ \\
\hline & PVC & $\begin{array}{l}\text { Polyvinyl chioride - Food trays, cling film, } \\
\text { bottles for squash, mineral water and } \\
\text { shampoo. }\end{array}$ \\
\hline & LDPE & $\begin{array}{l}\text { Low density polyethylene - Carrier bags and } \\
\text { bin Iners. }\end{array}$ \\
\hline & $P P$ & $\begin{array}{l}\text { Polypropylene - Margarine tubs, microwave- } \\
\text { able meal trays. }\end{array}$ \\
\hline & PS & $\begin{array}{l}\text { Polystyrene - Voghurt pots, foam meat or fah } \\
\text { trass, hamburger boaves and egg cartors. } \\
\text { vending cups, plastic cutlery, probective } \\
\text { packaging foe electronic goods and toys. }\end{array}$ \\
\hline & Other & $\begin{array}{l}\text { Any other plastics that do not fall inoo any of } \\
\text { the above categories. For example melamine, } \\
\text { often used in plantic plaves and cups. }\end{array}$ \\
\hline
\end{tabular}

\subsubsection{Types of plastic packaging}

\subsubsection{Polyethylene Terephthalate (PET/PETE)}

Pay attention to the code on the plastic packaging you buy. If there is a triangle with numbers or numbers in it, then the plastic is called polyethylene. Usually we find on mineral water pack, soy sauce bottle, cooking oil, chili sauce, and so on. There are several recognizable features of this type of PET / PETE plastic, such as clear, strong, solvent resistant, waterproof and gas, and easily soft at temperatures of 80 degrees Celsius. If used repeatedly, let alone to store hot water, polymer layer on the bottle it will melt and remove carcinogenic substances that can cause cancer. Therefore, this type of plastic packaging should be stored in a cool place and hid from a place that has temperatures above 80 degrees Celsius.

\subsubsection{High Density Polyethylene (HDPE)}

This type of plastic you can find on a plastic packaging marked with a triangle with number two in it. HDPE is usually found in detergent bottles, packing juices, oils, as well as some dairy packaging products. The HDPE traits you can recognize are semi flexible, chemically resistant, and moist. Although known to be quite safe from chemical reactions, but this type of HDPE plastic can turn soft if it is at a temperature of 75 degrees Celsius. HDPE is recommended for onetime use, as the release of antimony trioxide compounds continues to increase over time. Well this compound can cause skin irritation, respiratory problems, menstrual disorders can even cause a miscarriage for pregnant women, so need to be careful.

\subsubsection{Polyvinyl Chloride (PVC)}

This type of plastic may already be familiar enough among people in the form of a pipe or PVC pipe. This plastic type has a triangle image mark with the number three in it. However, make no mistake, it turns out that PVC is widely used to pack butter, margarine, and cooking oil because it is resistant to oil and has a low permeability to water and gas. PVC is also used to package hardware (hardware), cosmetics, and medicines. This PVC has strong properties and quite hard, but can turn soft if it is at a temperature of 80 degrees Celsius. PVC is widely used as clothing material, piping, roofing, and others. As a building material, PVC is relatively inexpensive, durable, and easy to assemble. However, PVC also contains hazardous components comprising Vinyl chloride monomer VCM), phthalate esters (DEHP, DIDP), Pb, and semi-carbide (SEM) compounds so they should not be used for storing food and beverages, as they contain diethyl hydroxylamine (DEHA ) that can damage the body organs of the kidneys and liver.

\subsubsection{Low Density Polyethylene (LDPE)}

Illustrated triangle and numbered four, this type of plastic is commonly called LDP, it is generally used as food wrapping plastic and supermarket plastic bags that you normally use. The nature of this plastic is strong, flexible, impermeable, the surface is not clear and can turn soft when it is at a temperature of 70 degrees Celsius. LDPE has a good protective capability against chemical reactions and is one of the most commonly used types of plastic to wrap food and beverages.

\subsubsection{Polypropylene (PP)}

Polypropylene you will find on plastic with triangular image numbered five. These plastics are usually found in food boxes, or medicine bottles. Bottles made of PP resistant to chemicals, heat and oil, but will soften at a temperature of 140 degrees Celsius. Polypropylene is the best type of plastic to be used as food and beverage packaging, as it prevents the occurrence of chemical reactions, and is quite resistant to hot temperatures.

\subsubsection{Polystyrene (PS)}

This type of Polystyrene plastic is also known as Styrofoam. This type of packaging has rigid, opaque, fat, and solventaffected properties, easily shaped and softened when it is at a temperature of 95 degrees Celsius. Styrofoam containers can be found as packaged frozen food, ready-to-eat dishes, can even be made as plates, forks, coffee packs and plastic 
spoons. Styrofoam is known to release styrene substances if heated especially when using a microwave. Because these styrene substances can cause brain damage, interfere with the reproductive system, to the nervous system. It is therefore advisable to avoid this type of packaging as food or beverage packaging.

\subsubsection{Polycarbonate}

Plastic type Polycarbonate is characterized by a triangular image with number seven. This plastic is a type of polycarbonate plastic (PC) with characteristics not easily broken, light, and clear. Polycarbonate is quite safe, and is often used in gallons of drinking water, even baby bottles, as long as it is not scratched and shows no signs of damage. Therefore, polycarbonate is basically not recommended anymore as food or beverage packaging, because it contains residual bisphenol $A$ (BPA) which is very dangerous for the body. The amount of chemical to be released depends on the temperature of the air at that time. Here is an example of plastic materials with product examples and explanations in the table 2, below:

Table 2. Plastic materials with product examples and explanations (Krisnadwi, 2013)

\begin{tabular}{|c|c|c|}
\hline No & Plastic Type & Information \\
\hline 1 & $\begin{array}{l}\text { Polyethylene } \\
\text { Terephthalat } \\
\text { e (PP) }\end{array}$ & $\begin{array}{l}\text { PET stands for polyethylene terephthalate - a durable, strong, lightweight, and easy to form polyester resin } \\
\text { when it is hot. the concentration is about } 1.35-1.38 \text { grams / cc, this makes it sturdy, the molecular formula } \\
\text { is (-CO-C6H5-CO-O-CH2-CH2 -O-) n. - Used for anything? PET can be found in water bottles, soda } \\
\text { bottles, juice bottles, cooking oil bottles, perfume, food packaging, salad dressing bottles and even coffee } \\
\text { cup cups } \cdot \text { Can it be recycled locally? In various places, places to recycle these plastics are available; even } \\
\text { they pick them up at a place for later after collecting they bring them to the recycling site. }\end{array}$ \\
\hline 2 & $\begin{array}{l}\text { High Density } \\
\text { Polyethylene } \\
\text { (HDPE) }\end{array}$ & $\begin{array}{l}\text { HDPE is High Density Polyethylene - a tough, strong, and rigid resin derived from petroleum, which is } \\
\text { often formed by blowing it. The molecular formula is (-CH2-CH2-) n. } \\
\text { - Used for anything? } \\
\text { HDPE can be found in milk kettles, detergent bottles, medicine bottles, engine oil bottles, shampoo bottles, } \\
\text { juice packs, liquid soap bottles, coffee packs and baby soap bottles. } \\
\text { - Can it be recycled locally? } \\
\text { Yes, plastic with label \# } 2 \text { can be recycled. In places, places to recycle these plastics are available, even } \\
\text { they pick them up at a place to then after they collect they take them to the recycling site. }\end{array}$ \\
\hline 3 & $\begin{array}{l}\text { Polyvinyl } \\
\text { Chloride } \\
\text { (PVC) }\end{array}$ & $\begin{array}{l}\text { PVC is Polyvinyl Chloride - The molecular formula is (-CH2-CHCl-) n. Other chemicals do not affect a } \\
\text { hard and hard resin. } \\
\text { - Used for anything? } \\
\text { PVC can be found in traffic signs, bottles of cooking oil, electrical cables, glass bottle cleaners, toys, } \\
\text { shampoo bottles, water pipes, wrinkle packs, and fast food packaging. } \\
\text { - Can it be recycled in place? } \\
\text { No. if possible, does not use it, or if forced to use it, use the former. }\end{array}$ \\
\hline 4 & $\begin{array}{l}\text { Low Density } \\
\text { Polyethylene } \\
\text { (LDPE) }\end{array}$ & 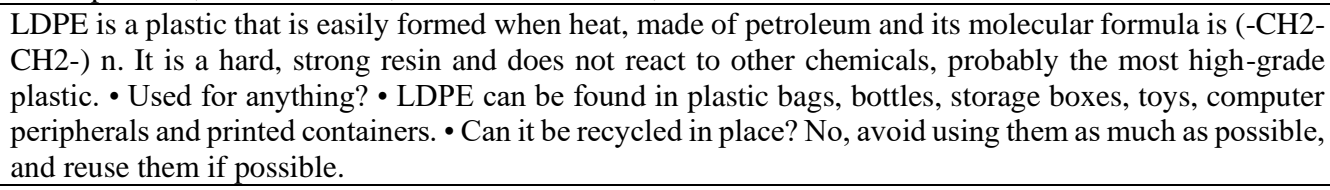 \\
\hline 5 & $\begin{array}{l}\text { Polypropylene } \\
\text { (PP) }\end{array}$ & $\begin{array}{l}\text { Polypropylene is a polymer plastic that is easily formed when hot; the molecular formula is (-CHCH3- } \\
\mathrm{CH} 2-) \text { n. The bending, hard and fat-resistant. - Used for anything? Polypropylene can be found in food } \\
\text { containers, packaging, plant pots, medicine bottle caps, margarine tubes, other caps, straws, toys, ropes, } \\
\text { clothes and various bottles. - Can it be recycled in place? No, avoid using them as much as possible, and } \\
\text { reuse them if possible. }\end{array}$ \\
\hline 6 & $\begin{array}{l}\text { Polystyrene } \\
\text { (PS) }\end{array}$ & $\begin{array}{l}\text { Polystyrene is a polymeric plastic that is easily formed when heated, the molecular formula is (-CHC6H5- } \\
\text { CH2-) n. Very stiff in room temperature. } \\
\text { - Used for anything? } \\
\text { Polystyrene can be found in plastics, CD boxes, plastic cups, food containers, and trays. } \\
\text { - Can it be recycled in place? } \\
\text { No, in the meantime, avoid using it as much as possible, and reuse it if possible. }\end{array}$ \\
\hline 7 & Other (mixed) & $\begin{array}{l}\text { Other Types } \\
\text { - What materials are used to make it? } \\
\text { Most often, products with label \# } 7 \text { are made from a mixture of two or more types of plastic (\# } 1 \text { through } \\
\text { \# 6). Sometimes label \# } 7 \text { indicates that the resin raw material is unknown. } \\
\text { - Used for anything? } \\
\text { It could be for all sorts of things, but most often you'll find plastic \# } 7 \text { used in the beverage or food industry } \\
\text { - Can it be recycled in place? } \\
\text { Unfortunately, plastic \# } 7 \text { cannot be recycled in the traditional way, so look for other alternatives. } \\
\text { After knowing various types of plastic and its properties, hopefully we can be more careful in using plastic } \\
\text { according to requirement and ability of plastic. Do not use heat-resistant plastic repeatedly. }\end{array}$ \\
\hline
\end{tabular}

\subsection{Forming Techniques: In-Line or Roll-Fed Thermoforming}

The in-line thermoforming process is designed to utilize hot plastic sheets that have been through the extruder. The plastic sheets are mechanically brought directly from the extruder through the oven to keep the sheet at the forming temperature and then to the forming station. The forming step should be synchronized with the takeoff speed of the extruder. This type of thermoforming is usually limited to 0.125 "or thinner sheets and applications that do not require optimal material 
distribution and tolerance. This process is more difficult to control than any other thermoforming process. The main drawback is that with the extruder and the former tied together in an angry mood one causing shutdown in both.

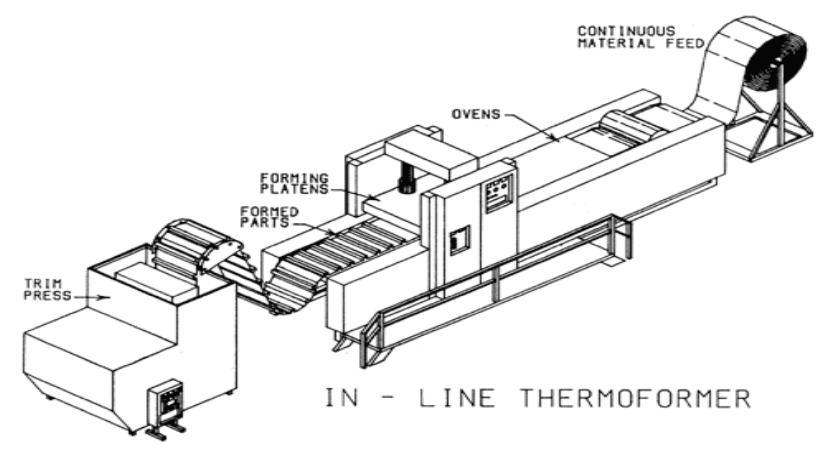

Figure 4. In-Line Thermoformer machine or inline machine(Empire West Inc., 2019)

The majority of roll-feed engines or in-line engines are typically used for the production of thin-walled products such as cups, trays, caps, internal packaging, and other finished products with a wall thickness of 0.003 "to 0.060 ". The speed of this secondary operation machine is incorporated in the unit, this may consist of printing, filling, sealing, cutting off, scrap cutting, or automatic removal, and stacking of finished products. Normal roll-fed machines consist of rolling stations, upper and lower heating banks, form stations, cooling stations, and trim stations Work principle. In theory, the working principle of thermoforming is quite simple. Heat Polystyrene sheets (HIPs), Polypropylene, or similar plastic or filament sheets, and by means of vacuum and air pressure, the sheets are pulled over the solid mold to obtain the desired shape. The majority of thermoforming production is with Fed Roll machines. Fed Sheet machines are used for smaller volume applications, and larger products. Plastic sheets softened in heating stations. Then forwarded to the molding station where the molding material is located. Thermoforming is the process of forming a flat thermoplastic sheet that includes two stages: softening the sheet with heating, followed by molding it in the mold cavity. Elastomers and thermosets cannot be formed by the Thermoforming method because of their cross-linked structure - it does not soften when heated.

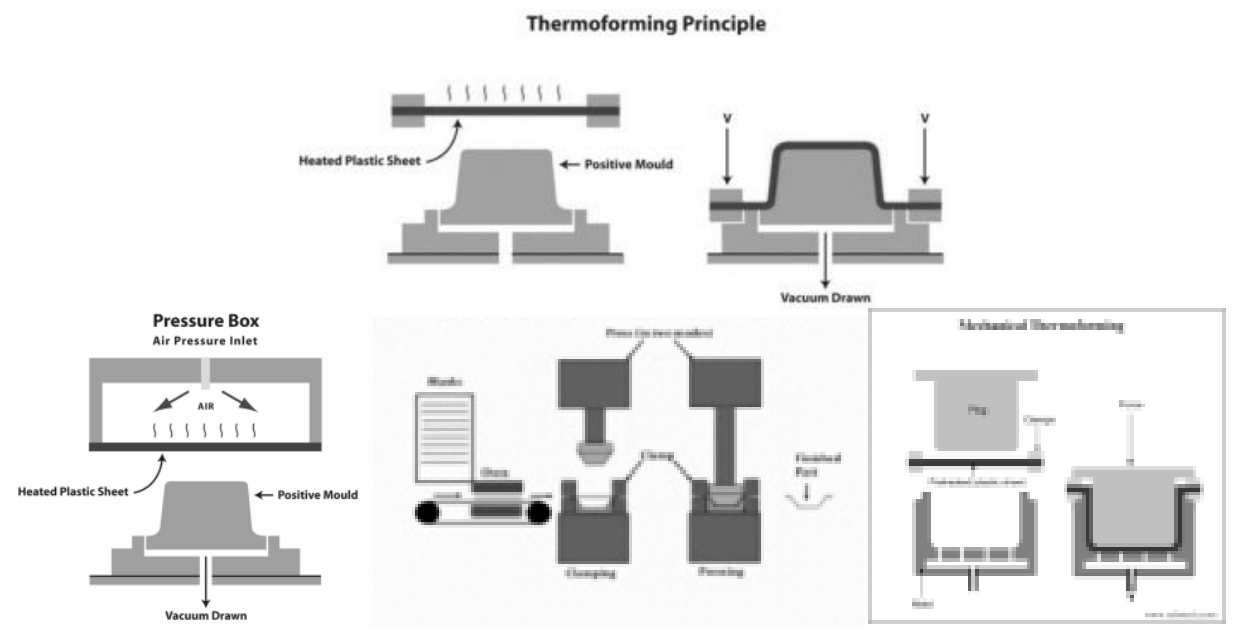

Figure 5. The working principle of thermoforming (Geoff, 2016; Kopeliovich, 2014)

Thermoplastics that can be processed by thermoforming methods are:

- Polypropylene (PP);

- Polystyrene (PS);

- Polyvinyl Chloride (PVC);

- Low Density Polyethylene (LDPE);

- High Density Polyethylene (HDPE);

- Cellulose acetate Polymethylmethacrylate (PMMA);

- Acrylonitrile-Butadiene-Styrene (ABS).

Thermoforming is widely used in the food packaging industry, manufacturing several pharmaceutical products and electronic products, toys, boat hulls, and many more products with plastic materials. There are three methods of thermoforming, different in the techniques used for the forming stage (Kopeliovich, 2014):

- Vacuum Thermoforming

- Pressure Thermoforming

- Mechanical Thermoforming 


\subsubsection{Vacuum thermoforming}

This process involves the formation of thermoplastic sheets that have been heated by means of a vacuum produced in the mold cavity space. The atmospheric pressure forces soft sheets to change shape according to the shape of the cavity. When the plastic is exposed to the mold surface, the machine cools and solidifies, as shown in the figure below.

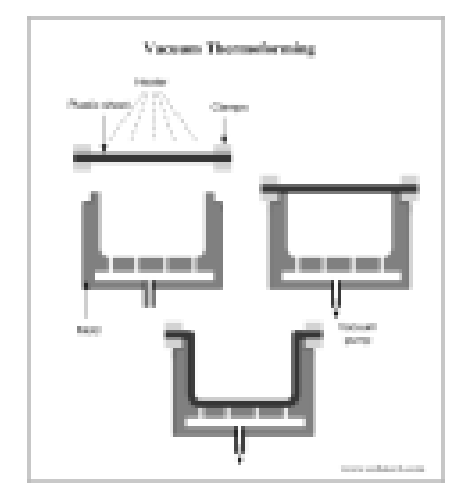

Figure 6. Vacuum forming process

\subsubsection{Pressure thermoforming}

This process involves the formation of preheated thermoplastic sheets using a pressurized spray. Air pressure forces soft sheets to change shape according to the shape of the cavity. When the plastic meets the mold surface, the machine cools and solidifies, as shown in the picture below.

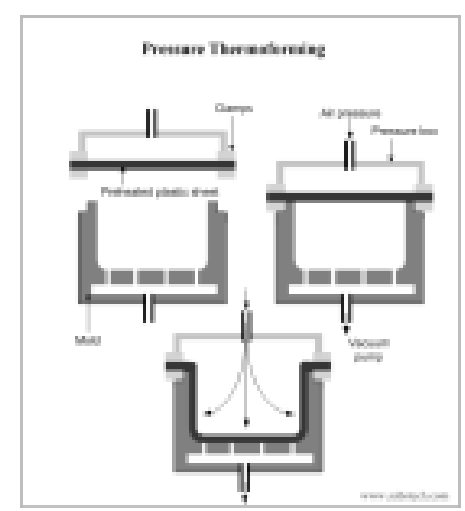

Figure 7. Thermoforming pressure process

\subsubsection{Mechanical thermoforming}

This process involves the formation of thermoplastic sheets that have been heated using direct mechanical forces. The use of the core plug / molding (positive molding) forces the soft sheet to fill the space between the plug and the negative print. The process provides dimensional tolerances and precise surface detail, as shown in the image below.

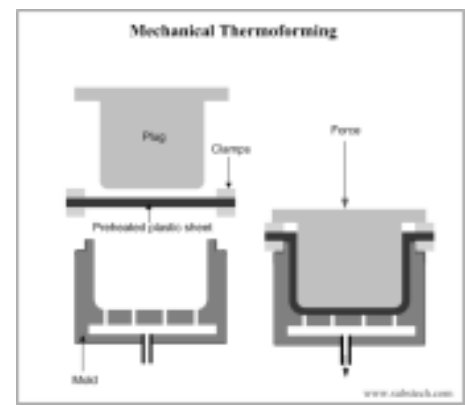

Figure 8 . Thermoforming pressure process

This activity is carried out to evoke various engineering potentials with their achievements. The results of this activity are set to use the thermoforming method to be used as the basis for the engineering design of the designed tool.

\subsection{Technical Engineering Analysis}

In this activity is conducted a study related to basic design engineering, namely method of thermoforming. The Thermoforming method is chosen after analyzing the overall known molding method for reasons of conformity with the design objectives. Then the Thermoforming method is analyzed based on suitability, ease, and device requirements used. So it was chosen to use the method of Vacuum forming based on the decision that the technique with this method is very 
easy to be realized for the SMEs due to the simplicity and simplicity of the process and the procurement of supporting equipment including the most easy to obtain in the area. The results of the assessment are shown in the table below.

Table 3. Aspect assessment matrix

\begin{tabular}{lllllll}
\hline No & Method & $\begin{array}{l}\text { Technical } \\
\text { aspects }\end{array}$ & $\begin{array}{l}\text { Process } \\
\text { aspects }\end{array}$ & $\begin{array}{l}\text { Aspects of } \\
\text { design }\end{array}$ & $\begin{array}{l}\text { Aspects of } \\
\text { equipment } \\
\text { tools } \\
\text { availability }\end{array}$ & Result \\
\hline 1 & Vacuum Thermoforming, & 1 & 1 & 1 & 1 & 4 \\
\hline 2 & Mechanic Thermoforming & 1 & 1 & 0 & 0 & 2 \\
\hline 3 & Pressure Thermoforming & 1 & 1 & 0 & 1 & 3 \\
\hline
\end{tabular}

Based on the results obtained showed that Vacuum Thermoforming becomes an option based on the aspect of ease of obtaining equipment to perform the most easily and cheap equipment design activities to be obtained in the area. Once defined the method used. Then the method is analyzed from several technical aspects of design such as; 1) methods of work/process; 2) technical methods; 3) design method. Referring to the process of vacuum thermoforming, the figure shows how the plastic is pulled or inhaled through the molding (negative) molding preparation and pressed with the (positive) molding plug done simultaneously after the plastic sheet has been heated.

The results of the analysis concluded that preparing the molding (negative) according to Kopeliovich method is very expensive, especially in the manufacture of molding (negatively). The design considers the inlet points i.e. the holes where the air passes have been trapped becomes in a difficulty level for small industries with mastery of technology that is still in a simple / concise stage and is applicative. Of course, this is a major consideration. Based on the deficiencies possessed by the method presented by Kopeliovich, then further study is done with the mirror technique that is doing the reverse process of the reference method. This method is made to be adapted to various forms of molding as printed reference. In the drawings presented technical method, which is the development of the method presented by Kopeliovich. It consists of two mechanical methods of mechanics, namely; 1) The lift / push-up method is similar to the Pressure Thermoforming method. The difference lies in the direction, i.e. on this method from the bottom or lifted using the levers. 2) Press method is similar to the method of Vacuum Thermoforming. The difference lies in the direction, i.e. on the method as described, i.e. molding is made object placed on the cross section (inlet). So, the placement of the inlet holes in the molding is no longer made. Here are the drawings of engineering design analysis of the concept of the method used as the basis of design.

\subsection{Product Trial Test}

\subsubsection{Hacking around objects}

The purpose of hacking the many items around us is to see if they can be made to make the packaging tool. Therefore, that IKM can make it happen with cheap cost without the need to buy the molding equipment with a very expensive cost. In addition, it aims to identify weaknesses with tolerances so that they are feasible to use.

\subsubsection{Trials using donut containers}

In the first trial tested to make the tool using plastic containers known by housewives as donut containers. The following trial using donut containers are described in the table 4 below.

Table 4. Trial using donut containers

\begin{tabular}{ll|l}
\hline No Activity / Process & Information \\
\hline 1 & Tools: \\
& - Drill \\
& - $1 \mathrm{~mm}$ drill bit \\
& - Glue gun / glue burn \\
& - Ruler \\
& Materials: \\
& Donut Container; $25 \mathrm{~cm} \mathrm{x} 25 \mathrm{~cm} \mathrm{x} 9 \mathrm{~cm}$ \\
&
\end{tabular}

\begin{tabular}{lll}
\hline 2 Making grids & $\begin{array}{l}\text { Mall points to be perforated made with a distance of } 1 \mathrm{~cm} \text {. At the bottom of the } \\
\text { container. }\end{array}$ \\
\hline $3 \quad$ Drilling & $\begin{array}{l}\text { The process of making holes in top the box by following the pattern made on } \\
\text { paper and then affixed. At the time of perforation, please note the direction of } \\
\text { drill perpendicular. This is to avoid split-flow. Results after perforated. The } \\
\text { result after the strip mall paper is removed. }\end{array}$ \\
\hline
\end{tabular}




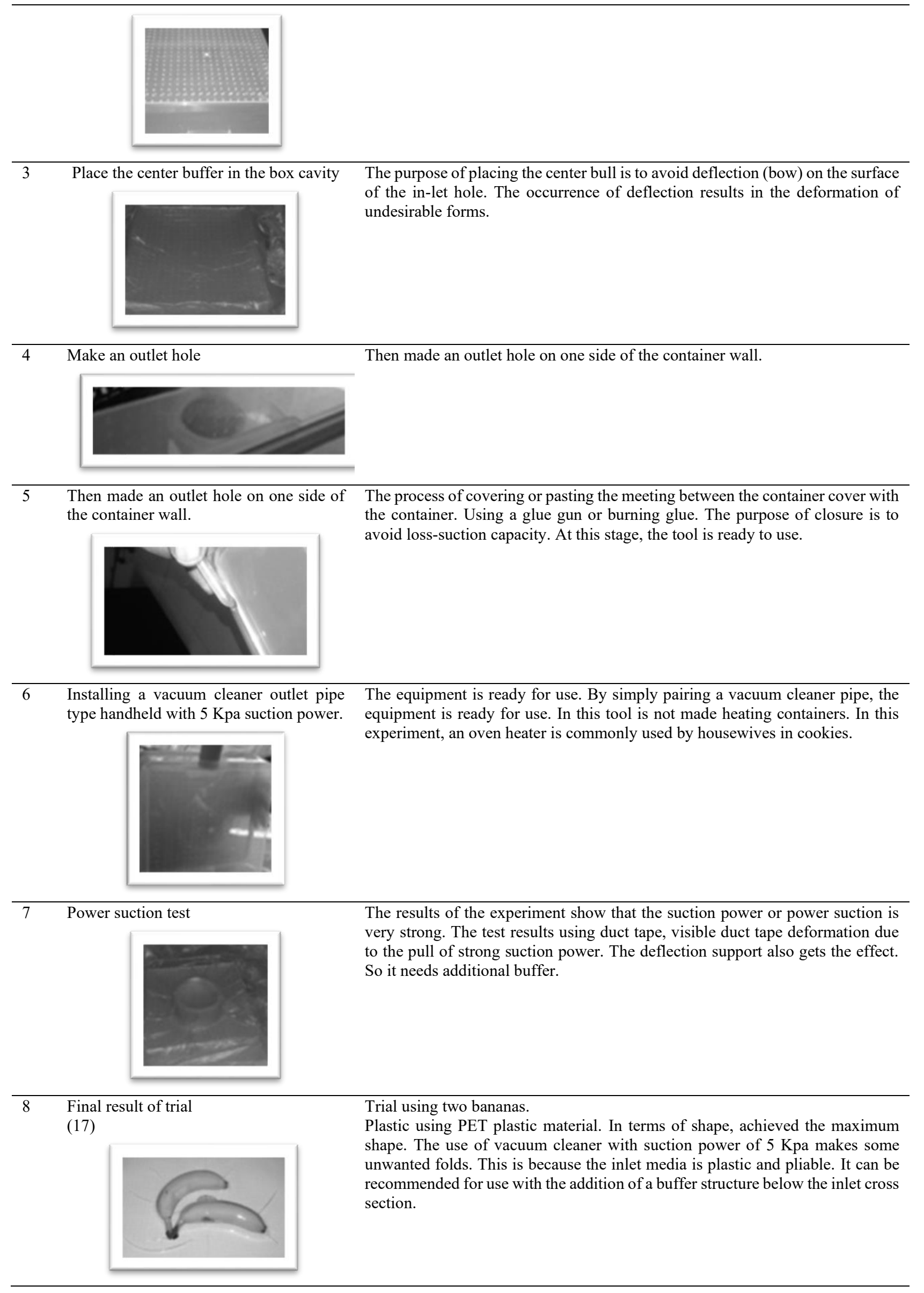

The advantages of using donut containers to hacking are easy to obtain and very familiar and the workmanship process using the material is easy. The shortage of donut container utilization is the plates or the surface of the inlet portion are fat, this is due to the plastic material and if with such structures many unwanted folds are produced on the printout. The recommendations on the use of donut containers are it is necessary to provide a buffer structure under the inlet cross 
section and producing a simple print product can be recommended using the donut container. Understanding the principle of making. In this trial test, it was decided to create a tool using standard materials according to the recommendation of the trial results based on the design objectives.

\section{CONCLUSION}

The production technology of packaging and other products based on plastic material is not as complicated as many people think. The technology is engineered based on the physical properties of a plastic that is melted if it is heat treated so it is easy to be formed. Understanding the basic concepts of engineering principles of equipment consisting of heating process and forming process using vacuum cleaner machine tool that is easily obtained and prepare the box facilities that can be obtained around us, the vacuum forming activity can be done. In accordance with the results obtained show that with simple equipment can produce a product that is useful to produce various types of packaging according to the form of creativity. These results also show that using this tool can produce not only the packaging that is the specific purpose of this research activity. However, it also has the potential to produce a wide range of other creative products.

\section{ACKNOWLEDGEMENT}

Gratitude to DRPM DIKTI (Directorate of Higher Education of the Republic of Indonesia) for funding this project. The authors express appreciation to the Rector of UNM, the head of UNM research institute, and the Dean of the Faculty of Arts and Design of UNM for their support. In addition, all the supports from staff, colleagues, students, and families during the project are truly appreciated.

\section{REFERENCE}

Anita. (2016). Desain Packaging Menentukan Nilai Produk. IKM Kemenperin. Retrieved from http://ikm.kemenperin.go.id/PUBLIKASI/bKumpulanArtikelb/tabid/67/arti \%0AcleType/ArticleView/articleId/5/DesainKemasan-Menentukan-Nilai- Produk.aspx

Badan Pusat Statistik Provinsi Sulawesi Selatan. (2017). Provinsi Sulawesi Selatan dalam Angka.

Buckle, K. A., \& Buckel, K. A. (1978). Food science. Australian Vice-Chancellors' Committee.

Empire West Inc. (2019). Forming Methods. Retrieved from https://www.empirewest.com/thermoforming-forming-methods.html Geoff. (2016). The Principle of Thermoforming. Retrieved from http://www.euroextrusions.com/the-principle-of-thermoforming/

Jaswin, M. (2008). Packaging Materials and its Applications. Jakarta: Indonesian Packaging Federation.

Julianti, E., \& Nurminah, M. (2006). Teknologi Pengemasan. Buku Ajar. Fakultas Pertanian Universitas Sumatera Utara.

Kemasaja Team. (2019). Kelebihan dan Kekurangan Kemasan berbahan Kertas dan Plastik. Retrieved from https://blog.kemasaja.com/2017/01/05/kelebihan-dan-kekurangan-kemasan-berbahan-kertas-dan-plastik/

Kertajaya, H. (2006). Marketing Plus 2000/SC Siasat Memenangkan Persaingan Global. Gramedia Pustaka Utama.

Klimchuk, M. R., \& Krasovec, S. A. (2018). Packaging design successful product branding from concept to shelf. Johanneshov: MTM.

Kopeliovich, D. (2014). Thermoforming. Retrieved from https://www.substech.com/dokuwiki/doku.php?id=thermoforming

Kotler, P. T., \& Armstrong, G. (2017). Principles of Marketing. Pearson Education. Retrieved from https://books.google.co.id/books?id=xOz0DQAAQBAJ

Krisnadwi. (2013). Mengenal Jenis-jenis Plastik. Retrieved from https://bisakimia.com/2013/01/03/mengenal-jenis-jenis-plastik/

Silayoi, P., \& Speece, M. (2004). Packaging and purchase decisions. British Food Journal, 106(8), 607-628. https://doi.org/10.1108/00070700410553602

Smith, P. R., Smith, P. R., \& Zook, Z. (2011). Marketing Communications: Integrating Offline and Online with Social Media. Kogan Page. Retrieved from https://books.google.co.id/books?id=MbCR0hBgYWgC

Supardi, I., \& Sukamto. (1999). Mikrobiologi dalam pengolahan dan keamanan pangan. Bandung: Alumni. Retrieved from https://www.belbuk.com/mikrobiologi-dalam-pengolahan-dan-keamanan-pangan-p-11857.html 